\title{
SYMPOSIUM ON RECENT ADVANCES IN ASTHMA
}

\author{
Held at Peterborough
}

on 7 November 1970

\author{
Chairman
}

R. S. JONES

M.D., M.R.C.P., D.C.H. Consultant Clinical Physiologist, Alder Hey Children's Hospital, Liverpool,
and Director of Studies, Institute of Child Health, University of Liverpool

\author{
Introduction \\ R. S. JONES \\ The immunological aspects of asthma \\ H. Amos \\ Biochemistry and rheology of sputum in asthma \\ E. E. KeAL \\ Mites and asthma \\ A. W. Frankland \\ Current therapeutic problems in asthma and its management \\ R. S. JONES \\ Bronchial lavage in asthma \\ Norton E. Williams
}

\section{Introduction}

\author{
R. S. JONES
}

Et causae quoque estimatio saepe morbum solvitCelsus. (To determine the cause of a disease often leads to the remedy.)

The cause of a disease and its remedy is not discovered overnight. Rather it is a long drawn out battle in which the abnormal mechanisms are pieced together one at a time and treatment is modified accordingly in the light of new knowledge. Hence from time to time it is appropriate to reappraise our views of the cause and cure of a disease.

Advances in our knowledge of the biochemical and physiological mechanisms in asthma, together with the introduction of new methods of treatment, justify the reappraisal of childhood asthma which is presented in this Symposium.

In the first paper Amos summarizes our knowledge of the mechanisms which cause bronchiolar muscle contraction and the mucosal response with excessive production of mucus. Keal reports recent work on sputum and draws comparisons between the findings in asthma and other diseases. Frankland summarizes our present knowledge of the role of mites in asthma and outlines ways in which they may be controlled. The salient physiological abnormalities are then outlined by Jones who goes on to consider details of management in the light of the various pathological mechanisms described previously in the Symposium. Lastly Williams deals with bronchial lavage and intermittent positive pressure ventilation, therapeutic measures to which one may have to resort when dealing with severe respiratory failure which has not responded to other methods of treatment. 